\title{
Astronomy to understand a human environment
}

\author{
By S. Isobe \\ National Astronomical Observatory, 2-21-1-Osawa, Mitaka, Tokyo 181, Japan
}

Astronomy is an important science in understanding a human environment. However, it is thought by most politicians, economists, and members of the public that astronomy is a pure science having no contribution to daily human activities except a few matters relating to time. The Japanese government is studying a reorganisation of our school system to have 5 school days per week, instead of 6 days per week, and this July its committee made a recommendation to reduce school hours for science and set up new courses for practical computers and environmental science. I currently made a proposal. It is very difficult for most of the school pupils, who will have non-scientific jobs, to understand science courses currently taught in school, because each science is taught independently from the other sciences. Therefore, their knowledge of sciences obtained during their school period does not greatly help their understanding of global environmental problems. We should present several stories to connect all the related sciences in order to give those pupils ideas in the understanding of global environmental problems. I believe that astronomy is able to play an important role in this context.

\section{Expansion of scientific items to be taught.}

Items which should be taught at school increase depending on time. Although items in language courses, mathematics courses, art courses and gymnastic courses increase little, those of social science courses increase gradually, but those in science courses do so drastically in recent decades. Therefore, it becomes much more difficult to teach all the necessary pupils. Pupils at the lower level of an elementary school have an interest in science, especially in astronomy. However, their interest is not in motions of the sun, moon, planets and starts on the celestial sphere, but in black holes, the big bang, star formation, comets and so on. Since in an elementary school and a junior high school, they are taught only about objects inside the solar system, they are gradually losing their interest in astronomy and also in science. In Japan, it has been said in this decade that most pupils do not now like science, because they are taught rather difficult scientific items. Figure 1 shows percentages of children, getting into a senior high school, and into a college, and a university, and these equivalences depending on time. Before 1960, only $10 \%$ of children went into a university level, and therefore, lecturers in a class at the lower level were not targeted for the pupils going to the university level. Teachers had the possibility to make an attractive lecture.

\section{New recommendations of governmental consulting committee for education.}

In 1947 after the second world-war, a completely new education system was introduced under the US occupation. Therefore, this system imitated the US education system. Since then, there have been 6 minor revisions. In all the cases, the number of school hours for science courses was gradually reduced. At the first stage, the science course was divided into 4 parts, namely physics, chemistry, biology and earth science. To set up earth science, there were deep discussions, and a conclusion was reached whereby 


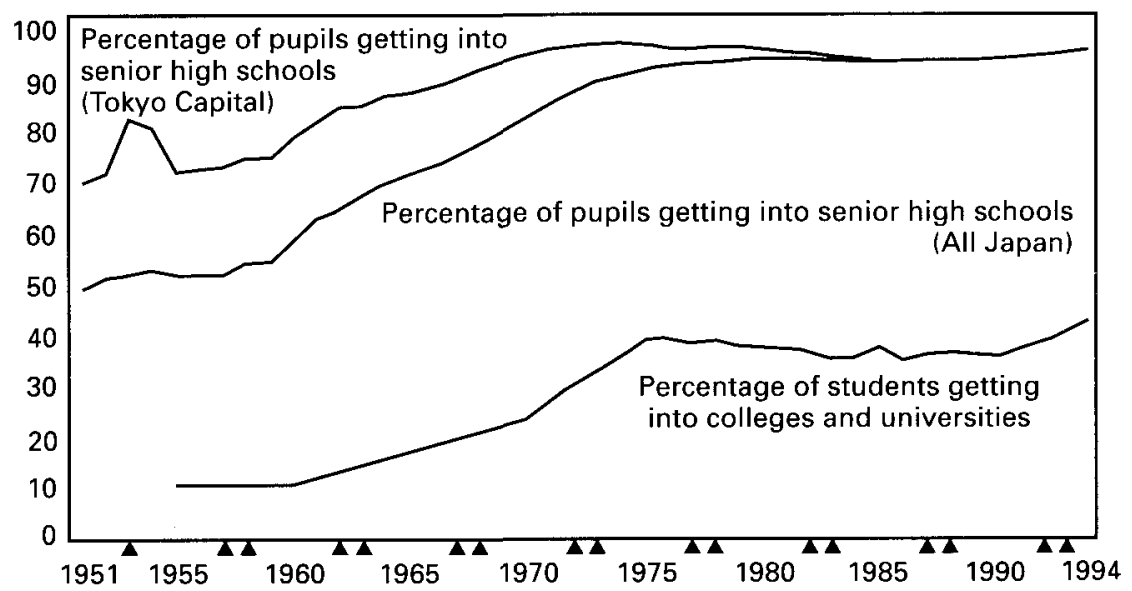

Figure 1. Growth in entry to Senior High School and University.

astronomy was included in it instead of in physics. In 1969, a new part was set up, fundamental science, which was changed to science I and II in 1988, and to integrated science in 1994. All efforts to combine all the science parts into one part were not successful. Form 1980 our government has requested companies to introduce 5 workings days per week. The number of companies having accepted this system is now over $80 \%$. To follow this up, the Japanese government set up a committee in the spring of 1995 to study a re-organization of our school system to have 5 rather than 6 school days per week, and the committee made a final recommendation to reduce school hours for science and introduce new areas such as practical computers (internet etc.) and environmental science this July. Although a final decision on school hours for each course will be made by a committee for school hour allocation, it will certainly start with school hours for science courses being reduced because of two effects, reduction of the total school hours and an addition of new courses. It will not be possible to teach the science being carried out as the present 4 parts of the science course, such as physics, chemistry, biology and earth science, with such reduced school hours. We need a drastic change of science course to meet this recommendation and to take into account matters in section 1.

\section{Proposed change for science course.}

It is very difficult for most school pupils, who will have non-scientific jobs, to understand science courses currently taught in school. As shown in Fig. 1, only $10 \%$ of all the pupils in 1960 went to university and about $5 \%$ of them became natural scientists and engineers. This ratio is probably not different between 1960 and the present. When one considers our scientific curriculum, school pupils are able to develop very high ability in science if they absorb all the scientific matter taught in a school class. Furthermore, physical, chemical, biological, and earth science phenomena are taught independently. However, since science phenomena which pupils see in their daily life are combinations of those phenomena, and there is practically no case of purely physical, chemical, biological and earth science phenomena, school pupils feel that their knowledge of sciences obtained during their school period does not much help their understanding of daily life sciences. For example, since an electric microwave oven is used to heat up food, it may sometimes happen that one tried to dry the wet hair of cat using this oven. There is no ability to combine the two pieces of knowledge of microwave and heating despite being 
taught both items at school. These years, there are many discussions and also activities on environmental problems by so-called environmental groups. However, because of their shortage of ability to combine different areas of scientific knowledge, it happens many times that they take out garbage from their area (e.g. their own houses) but move it to another (e.g. their neighbor's house). That is, we are not able, these days, to escape from global environmental problems: one should always consider whether an action to solve an environmental problem does or does not affect the global environmental problems. To solve these matters, I will propose a way in which 20 to 50 stories to connect all the related sciences should be prepared in order to give those pupils idea in understanding global environmental problems. As examples, we can prepare the following stories. 1) The cycle of water, 2) Solar light, 3) Rise and decline of the dinosaurs and 4) Shape of the Earth.

Each story should contain physical, chemical, biological and earth scientific items, mixing items from each part. Astronomy is able to play an important role in this context. For the example 1), water was collected on the Earth when it was formed from asteroid and comet collisions during its early history and those collisions are seen today as meteors, fireballs, and asteroid collisions forming craters. For the other examples, we are also able to include astronomical items. It is not necessary for pupils to learn all the stories. They can choose several stories for each grade. One can increase slightly difficult items for each story depending on the grade and also include new topical items such as the event of the Shoemaker-Levy 9 comet. Then, pupils can enjoy interesting scientific items and also learn the inter-relation of 4 parts of sciences. We should also prepare a curriculum for pupils who have good scientific ability and a high possibility to be scientists or engineers. This type of pupil should learn fundamental items and methods of 4 parts of sciences. Amounts of fundamental items increase depending on grade during a period of elementary school, but at a grade of junior and senior high school we should prepare a different curriculum for those two types of pupils.

\section{Conclusion.}

Pupils who have the ability to be scientists and engineers can enjoy the current curriculum. Therefore, we should prepare this fundamental scientific curriculum. Pupils who will have non-scientific jobs can also enjoy a new curriculum with stories as described above, and get an understanding of the importance of science, both in everyday life and as applied to global environmental problems. 